\title{
Quantitative analysis of fresh tomatoes (Solanum lycopersicum) for trace of pesticide residues from markets in Peshawar, Pakistan, using High Performance Thin Liquid Chromatography technique
}

\author{
Syeda Kokab Shah ${ }^{1}$, Syeda Faryal Israr ${ }^{1}$, Asif Khan Khatak ${ }^{1}$, Abeer Kazmi ${ }^{2,3,4, *}$, Amir Ali, ${ }^{3,4}$, Sher Mohammad ${ }^{3}$, \\ Muhammad Irfan ${ }^{4,5}$
}

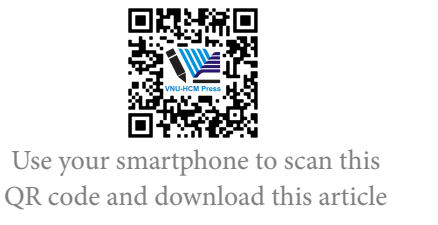

${ }^{1}$ Department of Environmental Sciences, University of Peshawar, KP, Pakistan

${ }^{2}$ College of Life Sciences, Wuhan University, Wuhan, PR China

${ }^{3}$ Biotechnology Lab, Agricultural Research Institute (ARI), Tarnab, Peshawar, Pakistan

${ }^{4}$ Department of Biotechnology, Faculty of Chemical and Life Sciences, Abdul Wali Khan University Mardan (AWKUM), Mardan 23390, Pakistan

${ }^{5}$ Nanobiotechnology research group, National Institute for Biotechnology and Genetic Engineering (NIBGE), Constituent College of Pakistan Institute of Engineering and Applied Sciences (PIEAS)University, Pakistan

Correspondence

Abeer Kazmi, College of Life Sciences, Wuhan University, Wuhan, PR China

Biotechnology Lab, Agricultural Research Institute (ARI), Tarnab, Peshawar, Pakistan

Department of Biotechnology, Faculty of Chemical and Life Sciences, Abdul Wali Khan University Mardan (AWKUM)

Mardan 23390, Pakistan

Email: abeer_kazmi@yahoo.com

\section{History}

- Received: Jun-26-2020

- Accepted: Sep-20-2020

- Published: Sep-30-2020

DOI : 10.32508/stdj.v23i3.2470

\section{Check for updates}

\section{Copyright}

(๑) VNU-HCM Press. This is an openaccess article distributed under the terms of the Creative Commons

Attribution 4.0 International license.

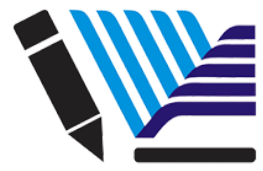

VNU-HCM Press

\begin{abstract}
Background: Vegetables and fruits are vital constituents of human diet, as it provides necessary minerals and nutrients to human body to carry out biological reactions and provide protection against various diseases and injuries. Solanum lycopersicum (tomato) is consider as cash crop in Asian countries and are fine source of vitamin C, potassium, folate, vitamin K, and other bioactive compounds including, phenolics, flavonoids, carotenoids, and alkaloids. Similar to other crops, tomato quality and yield is also affected by pests. Globally, approximately $37.8 \%$ of tomato yield is spoiled due to pests. To maintain the vegetable quality and attain more yields, pest management approaches are applied, though extensive use of toxic pesticides are becoming a part of our food chain and causing adverse effects. Methodology: The present research is intended to evaluate the levels of toxic pesticides in different tomato varieties collected from four vegetable markets (Hayatabad Phase 1, Chargano Chowk, Kohat Road and Tarnab farm) in Peshawar, Pakistan. After collection of tomato samples, level of pesticide residues (Cyhalothrin, Cypermethrin, Chlorpyrifos, Bifenthrin, and Imidacloprid) were detected using high performance thin liquid Chromatography (HPTLC). Results: After detection, level of pesticides in sample was compared with Maximum residue levels (MRLs). The magnitude of pesticides in samples was lesser to the Maximum residue levels (MRLs) provided by United State Drug Agency (USDA), though the quantity of Lambda Cyhalothrin present in the sample was almost equal to MRL $(0.097 \mathrm{mg} / \mathrm{kg})$. Conclusion: HPTLC is an efficient approach to detect pesticide traces in fruits and vegetables. Research work should be focused on it, to identify and control farmer practices which are highly linked to pesticide contamination in tomatoes and use of biopesticides should be encouraged. The cultivation of transgenic tomatoes can also be an efficient approach to elude the utilization of toxic pesticides. Key words: Tomato, Pesticide residues, HPTLC, MRL
\end{abstract}

\section{INTRODUCTION}

Vegetables and fruits are the major source of vitamins and minerals required by the human body to perform various biological reactions and functions. The vegetable are also the source of bioactive metabolites which are used to treat different infectious and chronic diseases, such as obesity, tumor, and renal complications, cardiac and hepatic problems ${ }^{1-5}$. During development stage of fruit and vegetable and post harvesting storage, vegetable and fruits are infected by the pests and ultimately lessens the yield. Therefore, toxic pesticides are sprayed to avoid the attack of pests. Due to minimal labor input, rapid and vast action, exploitation of pesticides is increased ${ }^{6}$. Though, at early stages of plant development the intense use of pesticides direct the plant to accumulate residues. The plant surface absorb pesticides (root surfaces and waxy cuticle) and integrate to the trans- port system of plant (systemic) or accumulate on plant surface (contact) and cause oxidative stress ${ }^{7,8}$.

To control pests, the use of pesticides are helpful but in return pesticides open the gateways for new kind of crisis including loss of biodiversity, damage to bio-control agents, insect resistance to pesticides, accumulation of toxic components in food chain and contamination of air, soil and water ${ }^{9}$. Pesticides residues can stay in human body for long time and cause prolonged effects, such as abnormal births, cancer, hepatic and renal problems, cardiac omplications, Asthma, Parkinsonism and Alzeheimer's development $^{10}$. Nausea, blurred vision, vomiting, coma, trouble in breathing and deficit hyperactivity disorders are the common other side effects of pesticide residues ${ }^{11}$. The flow of these compounds in the food chain and environment also occurs because of their lavish, unplanned, mishandling and indiscriminate
Cite this article : Shah S K, Israr S F, Khatak A K, Kazmi A, Ali A, Mohammad S, Irfan M. Quantitative analysis of fresh tomatoes (Solanum lycopersicum) for trace of pesticide residues from markets in Peshawar, Pakistan, using High Performance Thin Liquid Chromatography technique. Sci. Tech. Dev. J.; 23(3):713-719. 
use $^{12}$. Despite all the adverse effects, the use of pesticides have been increased by $1169 \%$ during the last 20 years ${ }^{13}$.

Tomato, being a cash crop in Khyber Pakhtunkhwa is sprayed with different kinds of pesticides to minimize the crop injury due to various insect pests and thus ensure maximum production and quality. Therefore, this study was organized to analyze fresh tomatoes obtained from different areas of Peshawar city and check for residues of pesticides in it and issue recommendations in the light of the findings from this study.

\section{MATERIALS - METHODS}

\section{Sample Collection Sites}

For analyzing tomato samples for probable presence or absence of pesticides residues, samples were collected from four markets (Hayatabad Phase 1, Chargano Chowk, Kohat Road/ Ring Road Junction, Tarnab farm) located in Peshawar. After collection, all the samples were shifted to Pesticides Residue Laboratory, Agricultural Research Institute, (ARI) Tarnab Peshawar for analysis using 5 various pesticides testing mentioned in Table 1.

\begin{tabular}{lcc}
$\begin{array}{l}\text { Table 1: Selected pesticides for testing in residual } \\
\text { experiments }\end{array}$ & $\begin{array}{c}\text { Molecular } \\
\text { formula }\end{array}$ & Classification \\
\hline $\begin{array}{l}\text { Pesticides } \\
\text { name }\end{array}$ & $\begin{array}{l}\mathrm{C}_{23} \mathrm{H}_{19} \mathrm{ClF}_{3} \mathrm{NO}_{3} \\
\text { Lambda } \\
\text { halothrin }\end{array}$ & Pyrethroid \\
$\begin{array}{l}\text { Cypermethrin } \\
\text { Chlorpyrifos }\end{array}$ & $\mathrm{C}_{22} \mathrm{H}_{19} \mathrm{Cl}_{2} \mathrm{NO}_{3}$ & Pyrethroid \\
Bifenthrin & $\mathrm{C}_{23} \mathrm{Cl}_{3} \mathrm{NO}_{22} \mathrm{ClF}_{3} \mathrm{O}_{2}$ & Organophosphate \\
Imidacloprid & $\mathrm{C}_{9} \mathrm{H}_{10} \mathrm{ClN}_{5} \mathrm{O}_{2}$ & Pyrethroid \\
\hline
\end{tabular}

\section{Procedure for Extraction of Pesticides}

Fresh tomatoes collected from various markets and at $-4{ }^{\circ} \mathrm{C}$ were preserved. After one hour for further procedure the preserved samples were taken off. After thawing, samples were sliced with speed blender. Erlenmeyer flask of $500 \mathrm{ml}$ capacity was used where $100 \mathrm{~g}$ from chopped vegetable sample was added in it. Followed by anhydrous sodium sulfate $20 \mathrm{~g}, \mathrm{NaCl}$ $2.5 \mathrm{~g}$ and freshly prepared distilled ethyl acetate $70 \mathrm{ml}$ was added. The use of ethyl acetate was for extraction. For an hour the flasks were shacked. For separation of aqueous material from other solid materials (vegetable parts that were not soluble in ethyl acetate) Whatman fluted filter paper No.42 (Sigma-Aldrich) was used.

\section{Purification procedure}

Purification procedure was carried out to purify tomatoes extract. Pesticide residues were passed through different purification steps as pesticide residues were soluble in ethyl acetate. By passing through active charcoals extracted samples were purified. At $105^{\circ} \mathrm{C}$ for 4 hours charcoal was activated. One $\mathrm{ml}$ of extract was transferred in round bottom flask and pesticide residues were dissolved in acetone. Using rotatory evaporator sample was concentrated. Pesticide residues became concentrated after passing through rotatory evaporator and easy to identify. Concentrated samples were filtered through filter paper $(0.2 \mu \mathrm{m})$ and analyzed by HPTLC.

\section{Preparation of standards}

At Residue Laboratory pesticide standards were available in powder form in different percentages. In $1 \%$ methanol standard solution was prepared (Table 2 ).

\section{Techniques for High Performance Thin Layer Chromatography (HPTLC)}

For the detection as well as calculation of the concentration of pesticides high performance thin layer chromatography was used, using protocol designed by ${ }^{14}$. In brief, glass plates ( $0.25 \mathrm{~mm}$ thickness) were prepared. At $105^{\circ} \mathrm{C}$ for 30 minutes each plate was activated. Initially, various concentrations of standards were spotted, then after the development of plate the diameter and concentration of spot were noted. Between concentration and spot diameter a graph was drawn that was helpful in the assessment of pesticides in samples. Along with the standards the desired sample was spotted. Followed by placing plate in tank that contained ammonia and methanol as a mobile phase, to remove undesired material plate was placed in fume hood.

\section{Development of plate}

For the development of plate different techniques were followed as applying same detection procedures all pesticides are not detected. Some pesticides when observed under UV at $254 \mathrm{~nm}$ for 30 minutes gave florescence. But under UV light many other pesticides were not giving florescence so for the development of plate many other techniques were followed.

\section{Potassium iodide and O-tolidine}

O-tolidine and potassium iodide spray generate brown yellowish color. To note-down spot's diameter, coloring reagent spray was preferred. Color intensity of brown yellowish varies with respect to the concentration of pesticides in standards and sample spots. 
Table 2: Standard preparation for pesticides

\begin{tabular}{lcc}
\hline Standard \% available & Amount taken of standard (g) & Total volume (solvent) \\
Imidacloprid (95.03\%) & 0.105 & $10 \mathrm{ml}$ \\
Bifenthrin (97.03\%) & 0.103 & $10 \mathrm{ml}$ \\
Chlorpyrifos (97\%) & 0.103 & $10 \mathrm{ml}$ \\
Cypermethrin (92\%) & 0.108 & $10 \mathrm{ml}$ \\
Lambda cyhalothrin (96\%) & 0.104 & $10 \mathrm{ml}$ \\
\hline
\end{tabular}

\section{Enzyme Inhibition Method}

This method is applied for the development of those pesticides on plate which produce color by and $\mathrm{O}$ tolidine and potassium iodide but do not give florescence under UV light. Plate was placed for 15 minutes in bromine vapors. Plate was placed again in fuming hood for 45 minutes for removing exceeding vapors. For 30 minutes at $37^{\circ} \mathrm{C}$ Horse blood serum enzyme was sprayed on the plate. To eliminate the extra vapors from plate hot air steam was given. Then for developing color substrate solution was sprayed on the plate. Spraying step was done in an incubator.

Tiny blue spots appear beside the white background of the plate. Blue spots direct the existence of carbamate pesticides. The distance covered by the ethyl acetate and the pesticides spots was measured. To calculate concentration of pesticides, the area of spots was measured vertically and horizontally. Followed by the calculation of the Rf value was measured through this procedure.

It is worth mentioning that satisfactory results were generated using O-tolidine and Potassium iodide, therefore the technique of Enzyme Inhibition Method was not applied in our research.

\section{Identification of pesticides}

After developing the plate, presence of pesticide in extracted sample of vegetable was detected. If both standard retention factor and retention factor of samples pesticide were matched then it was determined that the sample was contaminated.

\section{Quantification of pesticide}

Quantification of pesticides through high performance thin layer chromatography was done for different concentrations by measuring the diameter of standards. Different samples were checked for plate development. Diameter measurement and comparison with the standards quantifies the amount and concentration of pesticide in samples.

\section{Statistical analysis}

Data was collected from three experimental replicates. Statistical calculations were carried out with the GraphPad Prism 5 (Graphpad Software, Inc.) and SPSS (Statistical Package for Social Sciences, IBM). The results are presented as mean values with standard errors $( \pm)$. The mean values were subjected to Duncan's multiple range tests and Student's t-test. Values of $\mathrm{p}<0.05$ were considered as significant.

\section{RESULTS}

\section{Retention factor for Pesticides residue}

Retention factor of each pesticide was calculated by running the standard samples on HPTLC plate. This factor was calculated by measuring the distance travelled by the spots and solvent. Thus, it is equal to distance travelled by the spot divided by distance travelled by the solvent. The spots of Cypermethrin and Chlorpyrifos pesticides traveled more distance $(8.8 \mathrm{~cm}$ and $8.7 \mathrm{~cm}$, respectively) as compare to other pesticides (Table 3 ).

\section{Concentration of pesticides in tomato sam- ples ( $\mathrm{mg} / \mathbf{k g})$}

All the samples of tomatoes, obtained from various markets had residues of various pesticides sprayed against insects. The statistical analysis using F-test indicated that significant differences existed in values calculated for concentrations of various residues of pesticides. The tomato samples accumulated maximum concentration of Bifenthrin and Lambda Cyhalothrin $(0.100 \pm 0.009 \mathrm{mg} / \mathrm{kg}$ and $0.097 \pm 0.006$ $\mathrm{mg} / \mathrm{kg}$, respectively). It indicates that both, Bifenthrin and Lambda Cyhalothrin are the most used pesticides, or the tomato plant can easily up take these pesticides as compare to others (Table 4). If the concentration of pesticides is compared on the basis of area from where the samples were collected, tomatoes from vegetable market of Chargano chowk and Kohat road contained the higher amount of pesticides residues (Figure 1). 
Table 3: Calculated retention factors for pesticides

\begin{tabular}{lccc}
\hline Pesticide name & $\begin{array}{c}\text { Distance travelled by spot } \\
(\mathbf{c m})\end{array}$ & $\begin{array}{c}\text { Distance travelled by the } \\
\text { solvent }(\mathbf{c m})\end{array}$ & Retention factor \\
Cypermethrin & 8.8 & 13 & 0.67 \\
Chlorpyrifos & 8.7 & 13 & 0.669 \\
Bifenthrin & 6.8 & 13 & 0.52 \\
Lambda cyhalothrin & 7.0 & 13 & 0.54 \\
Imidacloprid & 3.0 & 13 & 0.23 \\
\hline
\end{tabular}

Table 4: Pesticides concentration in Tomato samples obtained from different markets

\begin{tabular}{|c|c|c|c|c|c|c|}
\hline \multicolumn{2}{|c|}{ Tomato samples obtained } & \multicolumn{5}{|c|}{ Pesticides concentrations in $\mathrm{mg} / \mathrm{kg}$} \\
\hline & & Imidacloprid & Bifenthrin & $\begin{array}{l}\text { Lambda } \\
\text { Cyhalothrin }\end{array}$ & Cypermethrin & Chlorpyrifos \\
\hline 1 & Hayatabad & 0.091 & 0.105 & 0.096 & 0.018 & 0.062 \\
\hline 2 & Chargano chowk & 0.087 & 0.099 & 0.106 & 0.024 & 0.078 \\
\hline 3 & Kohat Road & 0.098 & 0.108 & 0.097 & 0.014 & 0.077 \\
\hline 4 & Tarnab farm & 0.079 & 0.087 & 0.089 & 0.012 & 0.055 \\
\hline \multicolumn{2}{|c|}{ Mean } & $\mathbf{0 . 0 8 9} \pm \mathbf{0 . 0 0 7}$ & $0.100 \pm 0.009$ & $0.097 \pm 0.006$ & $0.017 \pm 0.005$ & $0.068 \pm 0.011$ \\
\hline
\end{tabular}

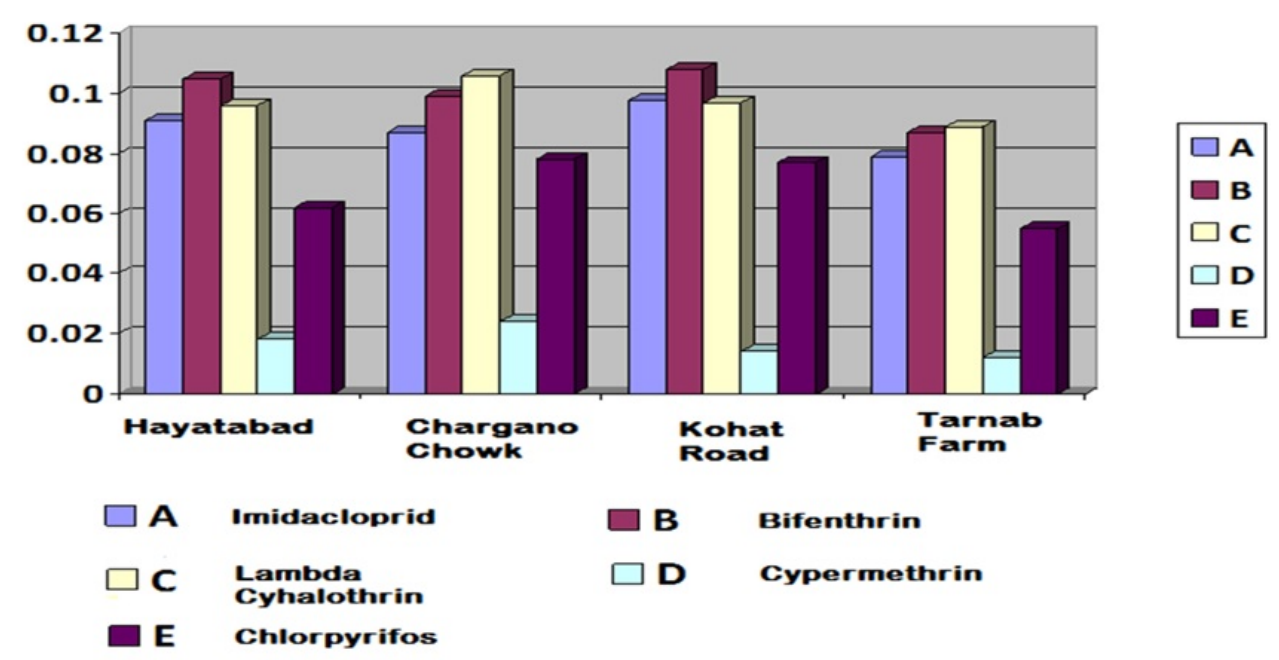

Figure 1: Bar diagram showing values of different concentrations of residues obtained across various locations for tomato samples in Peshawar city (results in $\mathbf{m g} / \mathbf{k g}$ ). 
Comparison of pesticides concentration in samples with maximum residue levels (MRL) ratified by United States Department of Agriculture (USDA)

The international permissible maximum residue levels (MRL) as approved by United States Department of Agriculture (USDA) for the observed pesticides (Lambda Cyhalothrin, Cypermethrin, Chlorpyrifos, Bifenthrin and Imidacloprid) in tomato samples are given in Table 5. Lamdba Cyhalothrin and Bifenthrin are the toxic pesticides and upon exposure it causes adverse effects on human health, therefore the MRL approved by USDA for Lamdba Cyhalothrin and Bifenthrin pesticides is limited to $0.10 \mathrm{mg} / \mathrm{kg}$ and $0.20 \mathrm{mg} / \mathrm{kg}$, respectively.

When compared with MRLs, it is clear that the detected concentrations of pesticides residues, present in tomato samples obtained from various locations in Peshawar city, are much lower than admissible level (Table 6). Though the residue of pesticide Lambda Cyhalothrin $(0.097 \mathrm{mg} / \mathrm{kg})$ is almost equal to MRL $(0.10 \mathrm{mg} / \mathrm{kg})$ (Figure 2), its use in tomato crop must be reduced so that the product remains safe for human consumption.

\section{DISCUSSION}

In Agriculture, various kinds of chemical pesticides are used to elude insect pest attack which may be deposited on fruit and vegetable surface and contaminate the product. If the calculated amount of pesticide exceeds the extreme residue perimeter of pesticides, then it can develop various kinds of diseases ${ }^{12,15,16}$. In the recent study, it was noticed that UV light gave florescence to Imidacloprid and Chlorpyrifos, the desired spots became detectable, similar to that determined by Munawar and Hameed, ${ }^{17}$. Pesticide classes such as pyrethroid, carbamates, and organophosphate, were determined by UV light ${ }^{18}$. We concluded that pesticides retention factor value can never be changed by any ecological factor or irrespective of time. Retention is measured by calculating the distance covered by the spot and the distance covered by the solvent. Retention factor calculated in current research work from HPTLC for Chlorpyrifos and Imidacloprid had similarity with the outcomes of $\mathrm{Mu}$ nawar et al. ${ }^{19}$. HPTLC can be run for detection of various types of pesticides by applying different coloring reagents ${ }^{20}$. In current research study, all the studied pesticides were present in tangible quantities, though none of them was found higher than international MRLs approved by USDA. The residue of pesticide Lambda Cyhalothrin $(0.097 \mathrm{mg} / \mathrm{kg})$ in collected tomato samples is almost equal to $\mathrm{MRL}(0.10 \mathrm{mg} / \mathrm{kg})$, these findings are in contrast to the results of Andrade et al. and Khan et al. ${ }^{21,22}$. Seven different vegetables namely onion, chilies, cauliflower, brinjal, bitter gourd, tomato, and okra were seriously affected and contaminated with emamectin benzoate, cypermethrin, lufenuron, endosulfan, profenofos, bifenthrin, diafenthiuron, and chlorpyrifos in Sindh, Pakistan ${ }^{23}$. Furthermore, every vegetable was contaminated with more than one pesticide and majority of samples violated the Japanese MRLs. The existence of these toxic compounds in the ecosphere and food chains also occurs because of their unplanned, excessive, unselective use and mishandling ${ }^{12,24}$. In contrast, pesticide application increased during the last 20 years by 1169 $\%{ }^{13,24,25}$. In Pakistan the maximum level of pesticides are being used in Punjab province (88.3\%), followed by Sindh (8.2\%), Khyber Pakhtunkhwa (KP) (2.8\%) and Balochistan $(0.76 \%)$. Out of these, only $11.9 \%$ pesticides are being consumed on vegetables and fruit crops $^{24,26-28}$.

\section{CONCLUSION}

Vegetable comprises a significant portion of the daily food intake of the human population. Customers mostly ask for better quality and fresh-looking vegetables with no observable rashes or holes affected by diseases or pests. To fulfill this demand, agriculturalists have to challenge pests and disease problems by all possible means, including use of pesticides which are hazardous to human health.

The current HPTLC method is an efficient and simple protocol that can be exploited for identification and quantification of pesticides in the given food sample. It is worth mentioning that satisfactory results were generated using O-tolidine and Potassium iodide, therefore the technique of Enzyme Inhibition Method was not applied in our research.

Further, in this research project, it was observed that pesticides residues (Lambda Cyhalothrin, Cypermethrin, Chlorpyrifos, Bifenthrin and Imidacloprid) were traced in all the tomato samples collected from different market places. The magnitude of these pesticides, when compared with USDA permissible level of MRLs was comparatively low. However, the quantity of Lambda Cyhalothrin present in the sample was higher to the MRL which is an alarming situation as the continuous consumption of these poisonous chemicals may accumulate in human body and may lead to serious consequences.

Further, the molecular based study of population consuming pesticides contaminated fruits and vegetables, is suggested. Research work should be focus on to 
Table 5: Maximum Residue Limit (MRL) provided by the United States Department of Agriculture (USDA) for the tested insecticides

\begin{tabular}{lcc}
\hline Pesticides name & Classification & MRL $(\mathbf{m g} / \mathbf{k g})$ \\
Lambda Cyhalothrin & Pyrethroid & 0.10 \\
Cypermethrin & Pyrethroid & 0.50 \\
Chlorpyrifos & Organophosphate & 0.50 \\
Bifenthrin & Pyrethroid & 0.20 \\
Imidacloprid & Neonicotinoid & 0.50 \\
\hline
\end{tabular}

Table 6: Comparison of observed values for various pesticide residues verses international MRLs

\begin{tabular}{lccccc}
\hline & \multicolumn{2}{c}{ Mean values for Pesticides concentration in $\mathbf{~ m g} / \mathbf{k g}$} \\
Imidacloprid & Bifenthrin & $\begin{array}{c}\text { Lambda } \\
\text { Cyhalothrin }\end{array}$ & Cypermethrin & Chlorpyrifos \\
Detected & 0.089 & 0.100 & 0.097 & 0.017 & 0.068 \\
MRLs & 0.50 & 0.20 & 0.10 & 0.50 & 0.50 \\
\hline
\end{tabular}

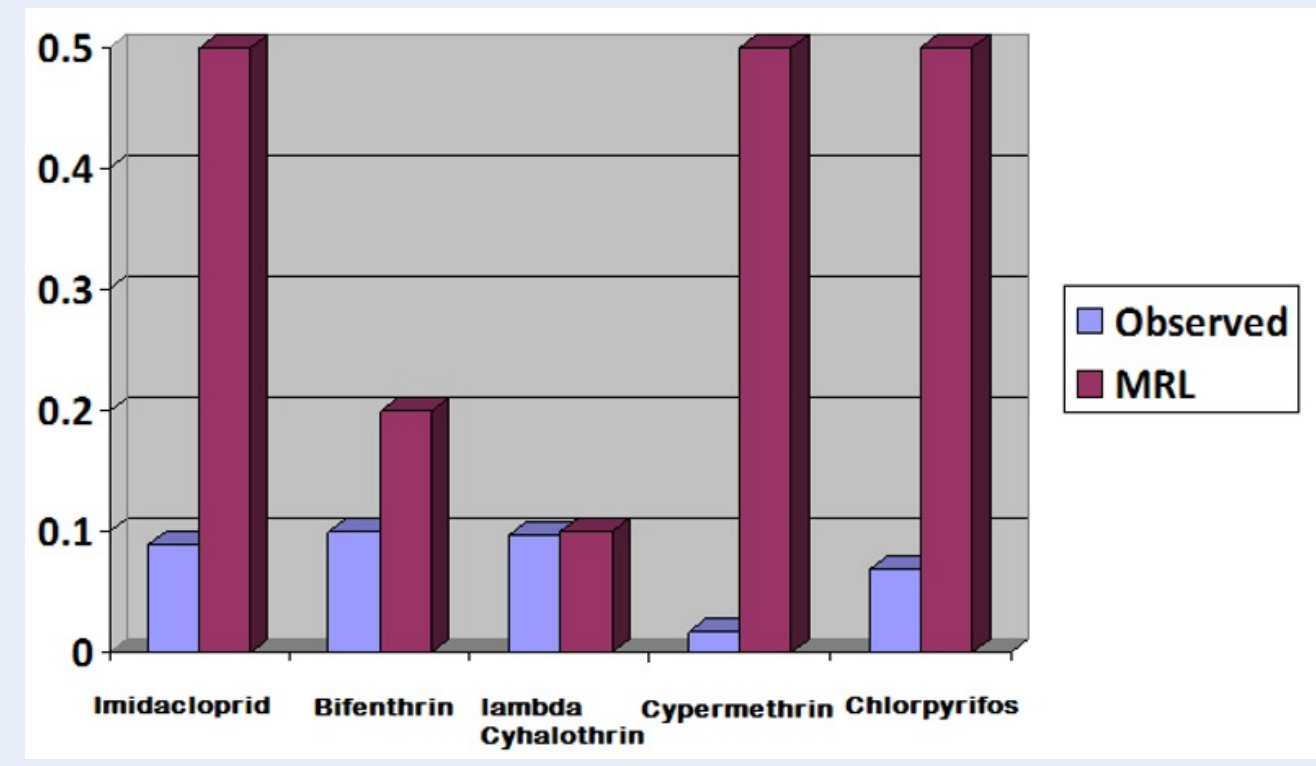

Figure 2: Comparative analysis of pesticide residues obtained from tomato samples in Peshawar with Maximum Residue Limits (MRLs) approved by USDA.

identify and control farmer practices which are highly linked to pesticide contamination in tomatoes and use of biopesticides should be encouraged. The cultivation of transgenic tomatoes can also be a substitute approach to overcome the usage of toxic pesticides.

\section{CONFLICT OF INTEREST}

All the authors declare no competing interest.

\section{AUTHORS' CONTRIBUTIONS}

Shah S K, Israr S F and Khatak A K, conceptualized study design, collected, analyzed and interpreted data. Kazmi A, Ali A, Mohammad S, and Irfan M. interpreted data, prepared manuscript and did proof reading. All authors read and approved the final manuscript. 


\section{ACKNOWLEDGMENT}

Authors are grateful to the Pesticides Residue Laboratory, Agricultural Research Institute (ARI), Tarnab Peshawar for their support and providing research facilities.

\section{FUNDING}

The current research work was not funded by any agency.

\section{REFERENCES}

1. Kazmi A, Usman M, Muhammad W. Effect of Hydroxybenzoic Acid Foliar Spray on Selected Wheat Varieties under Induced Heavy Metal Stress. Global Journal of Research and Review. 2019;6:1-4.

2. Mie A, Andersen HR, Gunnarsson S, Kahl J, Kesse-Guyot E, Rembiałkowska $\mathrm{E}$, et al. Human health implications of organic food and organic agriculture: a comprehensive review. Environmental Health. 2017;16(1):111. PMID: 29073935. Available from: https://doi.org/10.1186/s12940-017-0315-4.

3. Kazmi A, Khan MA, Mohammad S, Ali A, Kamil A, Arif M, et al. Elicitation directed growth and production of steviol glycosides in the adventitious roots of Stevia rebaudiana Bertoni. Industrial Crops and Products. 2019;139:111530. Available from: https://doi.org/10.1016/j.indcrop.2019.111530.

4. Kazmi A, Khan MA, Ali H. Biotechnological approaches for production of bioactive secondary metabolites in Nigella sativa: an up-to-date review. International Journal of Secondary Metabolite. 2019;6(2):172-195. Available from: https://doi. org/10.21448/ijsm.575075.

5. Kazmi A, Khan MA, Mohammad S, Ali A, Ali H. Biotechnological Production of Natural Calorie Free Steviol Glycosides in Stevia rebaudiana: An Update on Current Scenario. Current Biotechnology. 2019;8(2):70-84. Available from: https://doi. org/10.2174/2211550108666191210100751.

6. Angelo MJ. The law and ecology of pesticides and pest management. Routledge. 2016;Available from: https://doi.org/10. 4324/9781315556284

7. Yildiztekin M, Kaya C, Tuna AL, Ashraf M. Oxidative stress and antioxidative mechanisms in tomato (Solanum lycopersicum L.) plants sprayed with different pesticides. Pak J Bot. 2015;47(2):717-721.

8. Dubey G, Mishra N, Prasad SM. Metabolic responses of pesticides in plants and their ameliorative processes. Plant responses to xenobiotics: Springer. 2016;p. 57-95. Available from: https://doi.org/10.1007/978-981-10-2860-1_4.

9. Mahmood I, Imadi SR, Shazadi K, Gul A, Hakeem KR. Effects of pesticides on environment. Plant, soil and microbes. Springer. 2016;p. 253-269. Available from: https://doi.org/10.1007/9783-319-27455-3_13.

10. Kim KH, Kabir E, Jahan SA. Exposure to pesticides and the associated human health effects. Science of the total environment. 2017;575:525-535. PMID: 27614863. Available from: https://doi.org/10.1016/j.scitotenv.2016.09.009.

11. Gangemi S, Miozzi E, Teodoro M, Briguglio G, De Luca A, Alibrando $C$, et al. Occupational exposure to pesticides as a possible risk factor for the development of chronic diseases in humans. Molecular medicine reports. 2016;14(5):44754488. PMID: 27748877. Available from: https://doi.org/10. 3892/mmr.2016.5817.

12. Khan MJ, Zia MS, Qasim M. Use of pesticides and their role in environmental pollution. World Acad Sci Eng Technol. 2010;72:122-128.

13. Tariq MI, Afzal S, Hussain I, Sultana N. Pesticides exposure in Pakistan: a review. Environment international.
2007;33(8):1107-1122. PMID: 17765971. Available from: https://doi.org/10.1016/j.envint.2007.07.012.

14. Parvatamma B, Rao TN. A New Validated HPLC method for determination of Cyantraniliprole and its metabolite residues in tomato fruit. Asian Journal of Research in Chemistry. 2015;8(6):383-388. Available from: https://doi.org/10.5958/ 0974-4150.2015.00064.4.

15. Özkara A, Akyıl D, Konuk M. Pesticides, environmental pollution, and health. Environmental Health Risk-Hazardous Factors to Living Species. IntechOpen. 2016;Available from: https: //doi.org/10.5772/63094.

16. Khan SU. Pesticides in the soil environment. Elsevier. 2016;

17. Munawar A, Hameed S. Quantification of pesticide residues in vegetables by different chromatographic techniques. Journal of Chromatography \& Separation Techniques. 2013;4:1000200. Available from: https://doi.org/10.4172/2157-7064.1000200.

18. Fan H, Smuts J, Walsh P, Harrison D, Schug KA. Gas chromatography-vacuum ultraviolet spectroscopy for multiclass pesticide identification. Journal of Chromatography A. 2015;1389:120-127. PMID: 25757817. Available from: https: //doi.org/10.1016/j.chroma.2015.02.035.

19. Munawar A, Hameed SW, Sarwar M, Wasim M, Hashmi AS, Imran $M$. Identification of pesticide residues in different vegetables Collected from market of Lahore, Pakistan. Journal of Agro Alimentary Processes and Technologies. 2013;19:392398.

20. Meena AK, Sinha A, Verma S, Gupta M, Padhi M. HPTLC Profile of important Indian spices used in ayurvedic formulations. Research Journal of Pharmacognosy and Phytochemistry. 2013;5(4):188-193.

21. Andrade GCRdM, Monteiro SH, Francisco JG, Figueiredo LA, Botelho RG, Tornisielo VL. Liquid chromatographyelectrospray ionization tandem mass spectrometry and dynamic multiple reaction monitoring method for determining multiple pesticide residues in tomato. Food chemistry. 2015;175:57-65. PMID: 25577051. Available from: https://doi.org/10.1016/j.foodchem.2014.11.105.

22. Khan MS, Shah MM, Mahmood Q, Hassan A, Akbar K. Assessment of pesticide residues on selected vegetables of Pakistan. J Chem Soc Pak. 2011;33(6):816.

23. Sheikh S, Nizamani S, Panhwar A, Mirani B. Monitoring of pesticide residues in vegetables collected from markets of Sindh, Pakistan. Food Science and Technology Letters. 2013;4(1):41.

24. Syed JH, Alamdar A, Mohammad A, Ahad K, Shabir Z, Ahmed $\mathrm{H}$, et al. Pesticide residues in fruits and vegetables from Pakistan: a review of the occurrence and associated human health risks. Environmental Science and Pollution Research. 2014;21(23):13367-13393. PMID: 24958529. Available from: https://doi.org/10.1007/s11356-014-3117-z.

25. Bailey HD, Infante-Rivard C, Metayer C, Clavel J, Lightfoot $\mathrm{T}$, Kaatsch $\mathrm{P}$, et al. Home pesticide exposures and risk of childhood leukemia: Findings from the childhood leukemia international consortium. International journal of cancer. 2015;137(11):2644-2663. PMID: 26061779. Available from: https://doi.org/10.1002/ijc.29631.

26. Damalas CA, Khan M. RETRACTED: pesticide use in vegetable crops in Pakistan: insights through an ordered probit model. Elsevier. 2017;Available from: https://doi.org/10.1016/j.cropro. 2017.05.004.

27. Khan M, Mahmood HZ, Damalas CA. Pesticide use and risk perceptions among farmers in the cotton belt of Punjab, Pakistan. Crop Protection. 2015;67:184-190. Available from: https://doi.org/10.1016/j.cropro.2014.10.013.

28. Shahid M, Ahmad A, Khalid S, Siddique HF, Saeed MF, Ashraf MR, et al. Pesticides pollution in agricultural soils of Pakistan. Soil science: Agricultural and environmental prospectives. Springer. 2016;p. 199-229. PMID: 27403569. Available from: https://doi.org/10.1007/978-3-319-34451-5_9. 